lançamento desta obra, com apresentação pelo Prof. Bernardo Herold, Presidente do Grupo de História da Química, teve lugar a 9 de fevereiro de 2012, numa sessão comemorativa do Centenário da SPQ no Amphiteatro de Chimica da Escola Polytechnica (Museu de Ciência), em que para além de intervenções do Presidente e do Secretário-Geral, sobre o centenário e sobre o Ano Internacional da Química, respetivamente, foram apresentadas as palestras, "O futuro da Química: Desafios Orgânicos," pelo Dr. Nuno Maulide (Max-Planck-Institut für Kohlenforschung, Mülheim an der Ruhr, Alemanha) e "Afinidade Química: Antoine-Laurent Lavoisier e Mme Lavoisier," pelo Prof. Jorge Calado (Presidente da Comissão Nacional para o Ano Internacional da Química/ Centenário da SPQ).

Precisamente a 9 de maio, mas desta feita de 2011, ainda no mesmo espaço, fora feito o lançamento de um dos mais belos livros de química escritos em português, "Haja Luz! Uma História da Química Através de Tudo", da autoria do Prof. Jorge Calado (IST Press).

Um dos pontos altos de 2011 foi sem dúvida a realização do XXII Encontro Nacional, organizado pela Delegação de Braga da Sociedade Portuguesa de Química e pelo Departamento de Química da Universidade do Minho, numa comissão presidida pelo Prof. João Paulo André, que decorreu em Braga, no Parque de Exposições, de

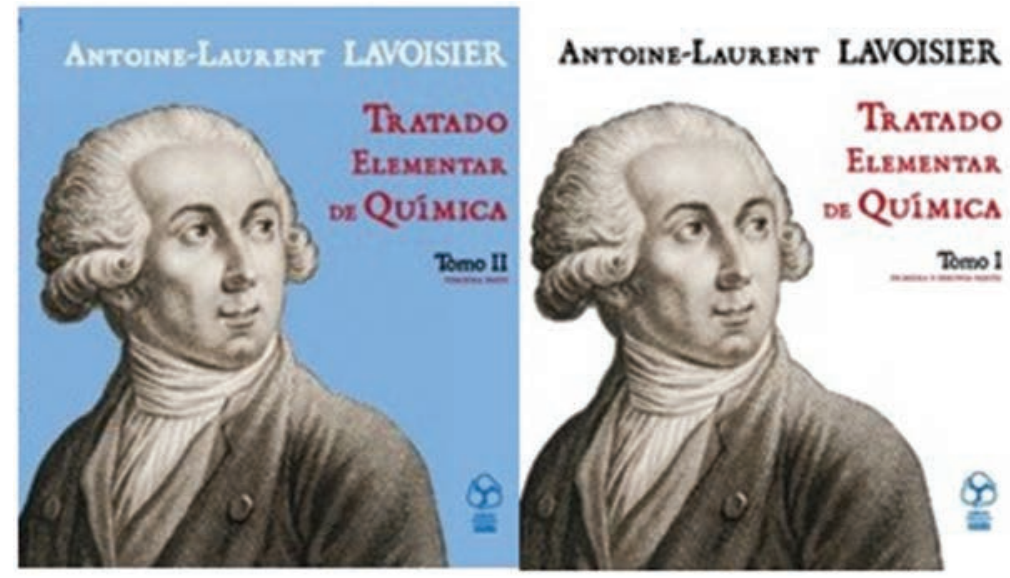

Capas dos dois volumes da tradução do "Tratado Elementar de Química"

3 a 6 de julho de 2011. O Encontro, subordinado ao tema "Cem Anos de Química em Portugal”, estava integrado nas comemorações do Centenário da SPQ e do Ano Internacional da Química e contou com o concurso das Divisões de Química Alimentar, Química Analítica, Química Física, Química Inorgânica, Química Orgânica e do Grupo de Radicais Livres, que viram realizados os seus encontros sectoriais sob a forma de Simpósios (respetivamente o $10 .^{\circ}$ Encontro de Química dos Alimentos, o 7. ${ }^{\circ}$ Encontro Nacional de Química Analítica, o 10. Encontro Nacional de Química Física, a 9. ${ }^{a}$ Conferência de Química Inorgânica, o 9. Encontro Nacional de Química Orgânica e o 8. ${ }^{\circ}$ Encontro do Grupo de Radicais Livres).

Durante o Encontro teve lugar a lição plenária do Prémio Ferreira da Silva, a cargo do Prof. Fernando Pina, tendo sido igualmente atribuída a Medalha Vicente Seabra ex aequo ao Dr. Eurico José da Silva Cabrita e ao Dr. José Richard Baptista Gomes. Pela primeira vez, foi também entregue o Prémio Romão Dias, no domínio da Química Inorgânica, à Prof. Maria José Diogo da Silva Calhorda.

Tudo isto e muito mais (ver QUÍMICA 120-125) contribuiu para que Portugal tivesse um dos mais extensos e completos programas para o Ano Internacional da Química.

Os resultados desse programa não serão facilmente mensuráveis ou visíveis, no entanto bastará que algures no futuro, um qualquer químico diga que foi naquele ano de 2011 que se apercebeu da sua vocação para que tenha valido a pena.

\title{
Apresentação da Tradução Portuguesa do Traité Élementaire de ChIMIE de Lavoisier
}

A Sociedade Portuguesa de Química encarregou o seu Grupo de História da Química de rever a tradução portuguesa do Traité Élementaire de Chimie. Como Presidente desse Gru-

\footnotetext{
Texto baseado na apresentação da obra, efetuada no dia 9 de fevereiro de 2012 no Amphiteatro de Chimica da Escola Polytechnica (Museu de Ciência, R. da Escola Politécnica, Lisboa)

** Presidente do Grupo de História da Química (herold@ist.utl.pt)
}

po coube-me fazer essa revisão final. $\mathrm{Em}$ face dum excelente manuscrito do autor da tradução, Emídio Queiroz Lopes, e das muitas utilíssimas notas marginais com que a enriqueceu, foram raras as questões a merecer uma troca de impressões. Apesar disso, a tarefa foi demorada, tendo que confessar-me por isso como o principal culpado de este lançamento ocorrer tão
Bernardo Herold**

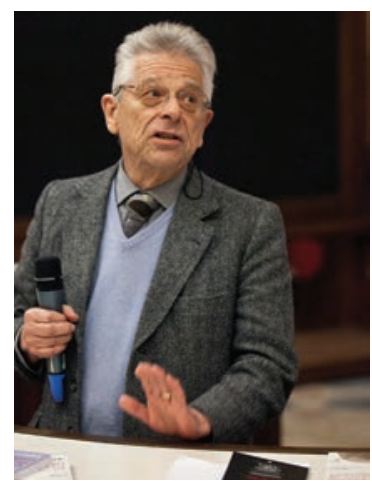


tardiamente. Suponho que haja poucos leitores que recentemente tenham lido o Traité com tanto pormenor como aquele a que fui obrigado. Essa leitura foi muito instrutiva em vários aspetos: embora seja evidente que a novidade do Traité tenha resultado da utilização consequente dos conhecimentos novos sobre o oxigénio e o seu papel na combustão e na formação das "cales", tal como a dos ácidos a partir dos elementos, bem como duma nomenclatura nova e sistemática, a leitura chamou-me também a atenção para outros aspetos normalmente menos valorizados. Lavoisier, além de dar essa arrumação diferente às matérias, usar uma sistematização e nomenclatura completamente novas e abandonar a doutrina do flogisto, também revela ao leitor um vastíssimo tesouro de conhecimentos químicos herdados do passado e apresentados por alguém com uma elevada competência, mesmo nas mais difíceis operações laboratoriais. Esse tipo de saberes só se pode adquirir trabalhando durante bastante tempo num laboratório químico sob a orientação dum profissional experiente. Isso sabe-se porque os estudos de inúmeras biografias de químicos revelam que não se encontra nenhum investigador, dentro de os que deixaram uma pegada significativa na história da química, que não tenha passado por essa experiência. Podem assim estabelecer-se autênticas genealogias de transmissão desses "segredos" da profissão. Quanto mais se recua no tempo, mais essas genealogias se fundem com as da medicina e farmácia, tendo grande parte delas a sua origem num dos grandes vultos da medicina renascentista das universidades do norte da Itália, como por exemplo em Falópio. Para Lavoisier também é possível encontrar uma genealogia dinástica. Frequentou o laboratório químico da farmácia de Guillaume François Rouelle (1703-1770) em Paris, que também foi demonstrador da cadeira de química do Jardin du Roi, mais tarde denominado Jardin des Plantes. Este jardim foi fundado em Paris no reinado de Luís XIII, em 1635, pelo médico Guy de la Brosse, como horto medicinal. Mas é, além disso, uma das mais antigas instituições oficiais de ensino em França, tendo tido logo desde o início três cadeiras: Botânica, Quími- ca e Anatomia. Embora, devido aos ciúmes da Sorbonne, não estivesse autorizado a conferir diplomas, tornou-se um local de aprendizagem da ciência mais moderna da época. Talvez mais ainda do que os catedráticos, foram os chamados demonstradores que transmitiam as artes dos boticários de manipularem substâncias químicas. Assim, Christoph Glaser, formado em medicina pela universidade de Basileia, ensinou no Jardin du Roi de 1660 a 1671, orientando o boticário Nicolas Lémery, que se tornaria o catedrático de Química de 1730 a 1743. Este teve como discípulo Johann Gottlieb Spitzley, boticário em Paris, em cuja farmácia estagiou o mestre de Lavoisier, Rouelle, que por sua vez foi demonstrador de Química no Jardin du Roi de 1743 a 1768. Curiosamente, o próprio Lavoisier nunca formou nenhum discípulo que se poderia considerar como continuador duma dinastia. A importância da herança recebida pelo convívio no laboratório com um mestre experiente nas operações químicas não está no entanto mencionada diretamente no "Discurso Preliminar", em que Lavoisier, antes pelo contrario, dá toda a importância à sua filiação na filosofia do Abade de Condillac (Étienne Bonnot de Condillac, 1715-1780), sobre as origens de todo o conhecimento humano nas sensações, como argumento a favor da importância das observações e medições na edificação da ciência química. A riqueza resultante da transmissão da experiência laboratorial através das gerações na formação de Lavoisier ainda assim se manifesta, em certa medida, na terceira parte do Traité "Descrição dos Aparelhos e das operações manuais da Química". Na introdução ${ }^{1}$, escreve "... estou longe de pretender que aqueles que queiram adquirir conhecimentos exactos em Química possam dispensar-se de seguir cursos, frequentar laboratórios e de se familiarizar com os instrumentos que se empregam. Nihil est in intellectu quod non prius fuerit in sensu: grande e importante verdade que nunca devem esquecer tanto aqueles que aprendem como os que ensinam e que o célebre Rouelle mandou escrever em grandes caracteres no lugar mais evidente do seu laboratório." Todo o Traité nos faz lembrar que foi escrito no Século das Luzes. O espírito com que nele Lavoisier aliou saberes existen- tes nas academias com as técnicas dos praticantes duma profissão teve claramente como modelo a Encyclopédie ou Dictionnaire raisonné des sciences, des arts et des métiers que Denis Diderot (1713-1784) e Jean le Rond D'Alembert (1717-1783) poucos anos antes tinham completado. É curioso notar que Diderot também se encontra entre os que frequentaram o laboratório de Rouelle. Um aspeto que também salta aos olhos de quem lê a terceira parte do Traité é a qualidade dos instrumentos laboratoriais descritos. Alguns são verdadeiras obras de engenharia! Só alguém com uma fortuna tão grande como a de Lavoisier e o poder que este exercia sobre as oficinas do arsenal do exército é que podia mandar construir aparelhos daquela complexidade!

Viremo-nos agora para a tradução em si: tal como mencionei no prefácio "Embora a obra tenha sido traduzida para várias línguas, pouco tempo após a sua publicação em Paris no ano de 1789 (entre 1790 e 1801 foram publicadas uma tradução inglesa, reimpressa várias vezes nos Estados Unidos, duas alemãs, uma holandesa, três italianas e duas espanholas), nunca foi, até agora, publicada nenhuma tradução portuguesa." Ao escrever o prefácio, não tinha todavia ainda conhecimento da publicação, quase simultânea, daquela que agora se apresenta, duma outra tradução do Discours préliminaire organizada e comentada por Palmira Fontes da Costa [1] e patrocinada pela Faculdade de Ciências e Tecnologia da Universidade Nova de Lisboa. Quanto à tradução do Traité na sua totalidade que agora se apresenta, um dos aspetos mais importantes tido em conta, tanto pelo tradutor, como na revisão, foi evitar anacronismos na terminologia. Por um lado havia o risco de, ao usar uma terminologia própria da época de cerca de 1800 , tornar a leitura do texto demasiado hermética. Por outro lado, uma terminologia moderna, mais familiar a um leitor de hoje, podia falsear a autenticidade da tradução. Para poder usar na tradução, na medida do possível, uma linguagem própria da época em que o Traité foi escrito, foi muito útil a consulta de duas obras fundamentais, ambas da autoria de Vicente Coelho da Silva Seabra e Telles (c.1764-1804), natu- 
ral do Brasil, nomeadamente os "Elementos de Chimica" [2] e a tradução e adaptação portuguesa de 1801 da Nomenclatura Química de Morveau, Lavoisier, Berthollet e Fourcroy [3]. Ainda há poucos dias a investigadora brasileira Alessandra Oliveira Harden, da Universidade de Brasília e do University College Dublin, me pediu uma cópia da introdução de Seabra à segunda destas obras. Devido à leitura dos seus trabalhos que me enviou [4], bem como do livro que nos seus artigos cita sobre a Casa Literária do Arco do Cego [5], estou em condições de acrescentar um pouco mais à especulação que fiz no prefácio sobre as razões de o Traité não ter sido traduzido em português durante a época em que se publicaram traduções em várias outras línguas europeias. As edições da Casa Literária do Arco do Cego, durante a sua efémera existência de 1799 a 1801 , albergou um projeto absolutamente ímpar no Antigo Regime de publicação de várias dezenas de traduções de obras científicas publicadas em francês, inglês, alemão e italiano. De acordo com os estudos que esta investigadora faz, das dedicatórias e prefácios destas traduções, este programa editorial constituiu uma tentativa de introduzir a ciência iluminista em Portugal debaixo do patrocínio do Príncipe Regente D. João. Os tradutores eram na sua grande maioria oriundos do Brasil e pertenciam à elite da Nação que duas décadas mais tarde se iria fundar. As obras destinavam-se claramente a instruir os jovens futuramente responsáveis pelo desenvolvimento económico do Brasil. As obras escolhidas eram assim de carácter eminentemente aplicado, incluindo as de matemática, visto estas se poderem justificar como indispensáveis para a prática da engenharia, da navegação e da cartografia. A nomenclatura química integrava-se perfeitamente neste espírito, dado que para fins alfandegários, fiscais e sanitários, era essencial que os nomes para as substâncias fossem rigorosos, não deixando margem para qualquer ambiguidade. É curioso notar que ainda hoje os utilizadores mais assíduos da nomenclatura IUPAC são a Organização Mundial da Saúde e as autoridades da União Aduaneira do espaço económico europeu e de outros espaços económicos. No prefácio apontei duas razões possíveis para o Traité não ter sido traduzido em português por volta de 1800. Uma das que citei foi o facto de os Elementos de Chimica de Seabra, publicados praticamente em simultâneo com o Traité, ser uma obra que já incorporava a química nova de Lavoisier. A outra foi ter-se publicado em 1801 a tradução, também de Seabra, da Nomenclatura moderna. Esta é mais do que uma tradução, mas antes um texto multilingue português, francês e latino que pode ser utilizado como dicionário, facilitando assim a um português a leitura do texto francês do Traité.

Sejam quais forem as razões de não se ter traduzido na mesma altura o Traité, não há dúvida que a tradução que agora se apresenta continua a ser muito oportuna. Cerca de 1800 teria sido muito útil a quem queria estudar a Química contemporânea. Agora, obviamente, o interesse é para quem estude a História da Ciência, em particular a da Química.

\section{EPílogo}

Posteriormente ao meu discurso de apresentação da tradução do Traité, um improviso que neste texto tentei reproduzir de memória, li com mais vagar os trabalhos acima citados sobre a Casa Literária do Arco do Cego e reli o discurso preliminar do Traité, bem como a introdução à terceira parte do mesmo. Daí julgo poder acrescentar mais algumas reflexões sobre as possíveis razões de o Traité não ter sido integrado no programa de traduções da Casa Literária do Arco do Cego, tão generosamente financiado pelo erário real através da influência do ministro D. Rodrigo de Sousa Coutinho.

Esse conjunto de traduções de livros de ciência iluminista obedeceu a um critério utilitário específico, tendo em vista a instrução dos jovens que futuramente seriam responsáveis pela economia do Brasil.

O Traité, pelo contrário, ultrapassa esses limites, ao fazer no discurso preliminar e em várias passagens a apologia do sensismo de Condillac. Esta tese gnosiológica era possivelmente vista pelos detentores do poder como demasiado controversa para que o Traité se pudesse considerar como destinado exclusivamente a finalidades úteis ao país e não para a propagação de ideias vistas como revolucionárias. Apesar de existir alguma plausibilidade nesta e nas outras explicações anteriormente mencionadas para o Traité não ter sido traduzido, não se pode tirar nenhuma conclusão segura sobre qual das possíveis razões terá pesado mais, ou se não terá havido outras.

\section{NotA}

${ }^{1}$ Na página 216 da tradução.

\section{REFERÊNCIAS}

[1] Palmira Fontes da Costa (org.), Manifesto para uma Nova Química, Palavrão, Associação Cultural. Chancela. Núcleo de Edição, Lisboa 2011.

[2] Vicente Coelho de Seabra, Elementos de Chimica, Real Officina da Universidade, Coimbra 1788 (Parte I e 1790, Parte II), edição facsimilada org. António J. Andrade de Gouveia, Departamento de Química da Faculdade de Ciências e Tecnologia. Universidade de Coimbra 1985.

[3] Vicente Coelho de Seabra Silva Telles, Nomenclatura Chimica Portugueza, Franceza e Latina, a que se ajunta o Systema de Characteres Chimicos adaptados a esta Nomenclatura por Haffenfratz [sic, em lugar de Hassenfratz] e Adet. (Tradução, e adaptação com uma introdução de Méthode de Nomenclature Chimique proposée par MM. de Morveau, Lavoisier, Bertholet \& De Fourcroy, Cuchet, Paris 1787), Typographia Chalcographica, Typoplastica e Litteraria do Arco do Cego, Lisboa 1801.

[4] Alessandra Ramos de Oliveira Harden, Brasileiro Tradutor e/ou Traidor: Frei José Mariano da Conceição Veloso, Cadernos de Tradução, 2009, 1/23, 131-148; Manoel Jacinto Nogueira da Gama: Ciência e Tradução no Final do Século XVIII, Tradução em Revista, 2010/1, 01-19, ISSN 1808-6195; Os tradutores da Casa do Arco do Cego e a ciência iluminista: a conciliação pelas palavras. Trab. linguist. apl. Campinas, 2011, 50/2, 301-320, ISSN 0103-1813.

[5] M. F. Campos (org.), A Casa Literária do Arco do Cego: Bicentenário (17991801). Biblioteca Nacional e Imprensa Nacional, Casa da Moeda, Lisboa 1999. 


\section{Antoine-Laurent LAVOISIER}

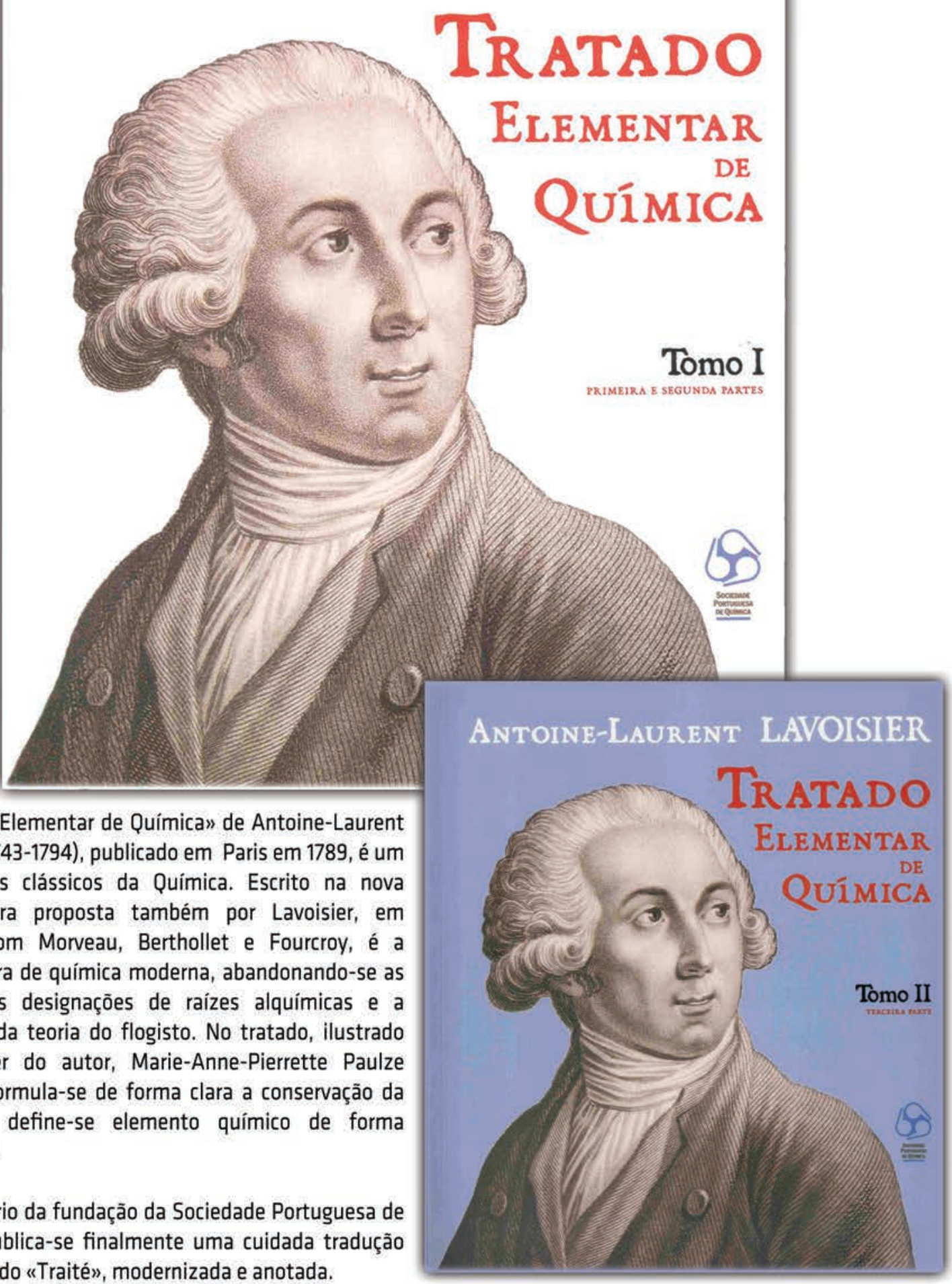

0 «Tratado Elementar de Química» de Antoine-Laurent Lavoisier (1743-1794), publicado em Paris em 1789, é um dos grandes clássicos da Química. Escrito na nova nomenclatura proposta também por Lavoisier, em conjunto com Morveau, Berthollet e Fourcroy, é a primeira obra de quimica moderna, abandonando-se as inadequadas designaçōes de raizes alquimicas e a desacreditada teoria do flogisto. No tratado, ilustrado pela mulher do autor, Marie-Anne-Pierrette Paulze Lavoisier, formula-se de forma clara a conservação da matéria e define-se elemento químico de forma operacional.

No centenário da fundação da Sociedade Portuguesa de Química, publica-se finalmente uma cuidada tradução portuguesa do "Traité», modernizada e anotada.

TOMO I e II

P.V.P.: 32 euros

Sócios da SPQ: 20 euros
ENCOMENDAS À SPQ

Av. da República $45,3^{\circ}$ esq - 1050-187 Lisboa Telefone: 217934637 email: sede@spq.pt 